BMJ Open Sport \& Exercise Medicine

\title{
What is the real impact of upper limb cast immobilisation on activity-related energy expenditure in children?
}

\author{
Albane B R Maggio, ${ }^{1}$ Xavier Eric Martin, ${ }^{2,3}$ Anne Tabard-Fougère, ${ }^{2}$ \\ Cécile Delhumeau, ${ }^{3}$ Dimitri Ceroni ${ }^{2}$
}

To cite: Maggio ABR, Martin XE, Tabard-Fougère $A$, et al. What is the real impact of upper limb cast immobilisation on activity-related energy expenditure in children? BMJ Open Sport \& Exercise Medicine 2018;4:e000359. doi:10.1136/ bmjsem-2018-000359

Accepted 29 August 2018
Check for updates

(C) Author(s) (or their employer(s)) 2018. Re-use permitted under CC BY-NC. No commercial re-use. See rights and permissions. Published by BMJ.

${ }^{1}$ Santé et Mouvement Consultation, Service of Paediatric Specialties, Department of Child and Adolescent, UniversityHospitals of Geneva and University of Geneva, Geneva, Switzerland ${ }^{2}$ Pediatric Orthopedic Unit, Department of Child and Adolescent, University of Geneva Hospitals, Geneva, Switzerland ${ }^{3}$ Clinical Epidemiology Service, Department of Child and Adolescent, University of Geneva Hospitals, Geneva, Switzerland

Correspondence to Dr Anne Tabard-Fougère; anne. tabard@hcuge.ch

\section{ABSTRACT}

Background Upper limb fractures and subsequent cast immobilisation constitute a potential cause of reduction in childhood levels of physical activity (PA), with subsequent decrease of energy consumption. The main objective of this study was thus to quantify the decrease of activityrelated energy expenditure (AEE) due to upper limb cast immobilisation

Methods We conducted a longitudinal matched casecontrol study that included 35 children and teenagers with a first episode of upper limb fracture and 35 healthy cases. PA was assessed during cast immobilisation by accelerometer. AEE was the calculated using an equation based on the total counts per day measured by accelerometers.

Results AEE in children and teenagers with upper limb fractures was estimated to be $7.4 \%$ lower than healthy controls. The mean difference corresponded to $1.35 \mathrm{kcal} /$ $\mathrm{kg}$ per mean valid recorded time (750 min), that is, the waking hours. When converted in kcal per mean subjects' weight, the difference in AEE amounted $63.5 \mathrm{kcal} /$ day, which corresponds approximately to 26 min of walking at a speed of $4 \mathrm{~km} /$ hours. In comparison with the mean AEE in healthy controls $(18.2 \mathrm{kcal} / \mathrm{kg})$, the noted decrease $(1.35$ $\mathrm{kcal} / \mathrm{kg}$ ) represents only $7.4 \%$ of AEE.

Conclusion Reduction of AEE in children and teenagers with upper limb fractures may lead to a slight positive energy balance, as there is usually no compensatory reduction of energy intake. An increase of light PA has to be counselled in this situation or patients should be advised to reduce their energy intake during the immobilisation period.

Level of evidence Level I: high-quality prospective study (all patients were enrolled at the same point in their disease with $\geq 80 \%$ follow-up of enrolled patients).

\section{INTRODUCTION}

Forearm fractures are the most common long-bone fractures in paediatric populations, comprising about $40 \%$ of all paediatric fractures. ${ }^{1-3}$ The distal parts of the radius and ulna are the most common locations for forearm fractures. ${ }^{4-10}$ Healthy children and teenagers commonly incur fractures during forceful trauma, such as falls from playground equipment or in sports activities. ${ }^{12}$ Most of
Key messages

What are new findings

Activity energy expenditure in children and teenagers with upper limb fractures was estimated to be $7.4 \%$ lower than healthy controls.

- The mean difference is estimated to represent 1.35 $\mathrm{kcal} / \mathrm{kg}$ during the waking hours.

- According to our findings, the amount of time needed to compensate for the energy gap induced by inactivity in our population would represent almost 26 minutes of walking at a speed of $4 \mathrm{~km} / \mathrm{hours}$ per day of immobilisation.

How might it impact on clinical practice in the future

- An increase of light physical activity has to be counselled in this situation or patients should be advised to reduce their energy intake during the immobilisation period.

- For the 6 expected weeks of immobilisation periods the consumption of the energy gap excess should require after cast removing 1 hour per day of extrawalking at a speed of $4 \mathrm{~km} /$ hours for 18 days.

the forearm/wrist's fractures are currently treated with cast immobilisation, and the most predictable consequences of cast immobilisation are decrease of physical activity (PA), loss of bone tissue and substantial muscle atrophy.

A decrease of PA is frequently associated with a sedentary lifestyle, such as long hours of watching television or playing computer games. ${ }^{2}$ Immobilisation of limbs with plaster cast represents another common cause of physical intermittent inactivity in children and teenagers. The response to injury's immobilisation may be sudden and severe, and induces muscle insulin resistance, whereas hyperinsulinaemia triggers hepatic lipogenesis. Calories spared by decreased PA, and muscle atrophy may be reallocated to fat production and storage in metabolically active central adipocytes, which induce life-saving hypercoagulation, platelet aggregation and inflammation. ${ }^{11}$ As there is usually 
no compensatory reduction of energy intake (quite the contrary), the situation may lead to a significantly positive energy balance, most of which is probably stored as fat, with detrimental health consequences. By being physically inactive for prolonged periods of time, children and teenagers also lose the opportunity to cumulate energy expenditure through the thousands of intermittent muscular contractions occurring throughout the 16 -hous wake period. ${ }^{13}$ In addition to the resulting decreased energy expenditure, a calorie surplus is often associated with a sedentary lifestyle. ${ }^{2}$ This caloric overload potentiates adipogenesis and subsequent overweight development with subcutaneous and ectopic fat deposition in several important organs, such as the liver, the muscles or the pancreas, leading to metabolic disturbances. ${ }^{12}$ Thus, PA is fundamental for children and teenagers' normal health and development. It has significant health benefits contributing to the prevention of cardiovascular diseases and acting as regulator of bone homeostasis. In contrast, physical inactivity is recognised as a risk factor for the development of obesity, type 2 diabetes, hypertension and cardiovascular diseases. ${ }^{13}$

In the current study, we quantified the decrease of activity-related energy expenditure (AEE) due to cast immobilisation for an upper limb fracture. We estimated also the daily amount of light PA required to compensate for the decrease in AEE encountered in fractured adolescents.

\section{MATERIALS AND METHODS Participants}

The study design was a longitudinal matched case-control study among 50 children and teenagers with an upper limb fracture and 50 healthy paired controls (no history of fracture) aged 10 to 16 years. The study was powered to quantify the decrease of AEE by using accelerometers in children and teenagers immobilised for an upper limb fracture. Injured children and teenagers were recruited among patients admitted in our hospital either for orthopaedic reduction or minimal invasive surgery of their upper limb's fracture under general anaesthesia. Healthy controls were for their part enrolled through advertisements placed at the Children's Hospital of Geneva, Switzerland. The control group was therefore sampled from the same geographical area than the subjects and would have been enrolled as study cases. Patients and healthy controls and their parents were informed by the principal investigator (DC) about the current project. Exclusion criteria for both injured adolescents and healthy controls were: prior history of bone fractures; chronic disease; congenital or acquired bone disease; any condition limiting PA (other than the fracture) and hospitalisation for more than 2 weeks in the previous 12 months. Patients who required an open reduction of their fracture with hardware placement were not eligible for inclusion. Participants were asked to wear an accelerometer continuously for 10 days. A consent form was available in multiple languages, and the authors ensured that the form was in a language that the children and teenagers could understand. All participants and their parents provided written consent and conforms to the provisions of the Declaration of Helsinki in 1995 (as revised in Tokyo 2004).

\section{Anthropometric measurements}

Standing height and body weight were measured with the child barefoot and wearing light clothes. Body mass index (BMI) was calculated as weight in $\mathrm{kg}$ divided by height in $\mathrm{m}^{2}$.

\section{PA measurement}

Accurate measurement of PA was assessed using a uniaxial accelerometer (Actigraph 7164, MTI, Fort Walton Beach, FL) for a 10-day period during cast immobilisation. Study's participants were asked to wear the device continuously for 10 days, and accelerometers were scheduled to start recording at 8.00 on the first day of measurement and to stop recording at 12.00 of the last day. The monitor was set on a 1 min cycle; at the end of each run, the sum was stored in the memory and the numerical integrator reset. Monitors were securable above the iliac crest of the right hip with an elastic belt and were oriented vertically in the same direction. As we did not have normative criteria for defining normal PA in children and teenagers, data from the age-matched and gender-matched healthy controls were considered as the base values.

\section{PA data interpretation}

Data reduction was realised by using criteria already applied in previous reports. ${ }^{14-17}$ Only the 13 hours waking day between 8.00 and 9.00 were analysed. Zero activity periods of $20 \mathrm{~min}$ or longer were interpreted as being due to unworn accelerometers and were removed from the activity totals. ${ }^{18}$ Participants who did not record more than $600 \mathrm{~min} \mathrm{~d}^{-1}$ of activity ${ }^{15177^{19-21}}$ for at least 5 days were excluded from further analysis ${ }^{22}$, and differences in PA were adjusted considering weekday and weekend.

\section{Calculation of AEE}

AEE was calculated using the equation developed by Puyau et $a l^{23}$ This equation has been validated in children and is based on the total count/min measured by accelerometer independent of age or gender. ${ }^{23} \mathrm{AEE}$ is expressed as the amount of $\mathrm{kcal} / \mathrm{kg} / \mathrm{min}$ according to the following equation:

$$
\operatorname{AEE}(\mathrm{kcal} / \mathrm{kg} / \mathrm{min})=0.0183+0.000010 \times \text { counts }
$$

The decrease of the injured patients' AEE was thus defined in $\mathrm{kcal} / \mathrm{kg}$ per day. To that point, we tried to convert this lack of energy expenditure in minutes of walking at a speed of $4 \mathrm{~km} /$ hours (energy expenditure $3.1 \mathrm{kcal} / \mathrm{kg}$ per hour) as well as to express it in caloric content of any classical foods. 
Table 1 Characteristics and physical activity measures of children and teenagers with upper limb fractures during cast immobilisation vs healthy controls

\begin{tabular}{|c|c|c|c|}
\hline & $\begin{array}{l}\text { Injured adolescents } \\
(n=35)\end{array}$ & $\begin{array}{l}\text { Healthy controls } \\
(n=35)\end{array}$ & $P$ values \\
\hline Age (year) & $12.56 \pm 1.67$ & $12.63 \pm 1.76$ & $(\mathrm{t}) 0.524$ \\
\hline Height $(\mathrm{cm})$ & $157.71 \pm 13.43$ & $157.72 \pm 11.76$ & $(\mathrm{t}) 0.999$ \\
\hline Weight (kg) & $47.30 \pm 12.12$ & $46.29 \pm 11.39$ & $(\mathrm{t}) 0.425$ \\
\hline BMI $\left(\mathrm{kg} / \mathrm{m}^{-2}\right)$ & $18.68 \pm 2.38$ & $18.35 \pm 2.52$ & $(\mathrm{t}) 0.261$ \\
\hline Number of valid monitored days & $8.71 \pm 2.36$ & $8.11 \pm 2.35$ & (w) 0.204 \\
\hline Daily duration of physical activity monitoring (min) & $752.08 \pm 26.76$ & $740.90 \pm 37.41$ & (w)0.318 \\
\hline Total activity (counts $/ \mathrm{min}^{-1} / \mathrm{d}^{-1}$ ) & $417.54 \pm 179.12$ & $597.09 \pm 211.35$ & $(w)>0.001^{*}$ \\
\hline Time spent in moderate to vigorous activity $\left(\mathrm{min} / \mathrm{day}^{-1}\right)$ & $42.06 \pm 21.64$ & $66.65 \pm 28.47$ & $(w)>0.001^{*}$ \\
\hline Activity energy expenditure AEE (kcal/kg per min) & $0.0225 \pm 0.02$ & $0.0243 \pm 0.02$ & (w) $0.003^{*}$ \\
\hline
\end{tabular}

A Shapiro Wilk test with an alpha threshold of $5 \%$ was used to test the normality of PA variables. Since PA variables did not have a normal distribution, our statistician used a paired Wilcoxon test $(\mathrm{w})$ with an alpha threshold of $5 \%$ in order to assess differences of PA levels between cases and controls. However, variables concerning matching characteristics were normally distributed. Thus, an unpaired Student t-test $(t)$ was used for these variables.

$\mathrm{AEE}$, activity-related energy expenditure; BMI, body mass index; PA, physical activity.

\section{Statistical analyses}

For logistical reasons and for improving compliance, no patients or control participants were included into the study during the holidays; thus PA measurements were recorded only during school periods. Similarly to precedent paper, ${ }^{24}$ patients and controls were matched according to age ( \pm 6 months), gender (male/female) and season. The participants characteristics used for matching were compared between groups using an unpaired Student's t-test. A Shapiro-Wilk test was used to reject the normality distribution of variables relative to PA. Thus, an unpaired Wilcoxon test was used to compare PA levels between cases and controls. Results were reported as mean $\pm \mathrm{SD}$ for all parameters. The imputation of the missing values was used only if the rate of missing values was lower than $10 \%$. Otherwise, rows were excluded to limit bias due to missing values. Data analyses were performed using STATA V.9.2 (StataCorp).

\section{RESULTS}

Fifteen children and teenagers with upper limb fractures were excluded either for failing to reach at least 5 days of measurement or for instrument malfunctions. Thirty-five patients with upper limb fractures were able to be matched with 35 healthy controls. Age, physical characteristics and PA levels of fractured' subjects and healthy controls have been previously published ${ }^{13}$ and are summarised in table 1 . There was no statistical difference between groups for age, height, weight, BMI or daily duration of PA monitoring.

As expected, cases with upper limb fractures showed notable lower PA levels and spent more time in sedentary activities. The total PA count (number of counts/min) was significantly lower in those with upper limb fractures $(-30.1 \%)$ compared with healthy controls. When considering time spent in moderate to vigorous PA, we observed less time $(-36.9 \%)$ in lower limb fracture groups compared with matched healthy controls (table 1). All these data are similar to those already reported in a previous publication. ${ }^{13}$

AEE was $7.4 \%$ lower in adolescents with fractures compared with controls. The mean difference corresponded to $1.35 \mathrm{kcal} / \mathrm{kg}$ per mean valid recorded time (750 min), that is, the waking hours. By extrapolating this calculation to the mean weight of the patients $(47$ $\mathrm{kg}$ ), it represents an energy gap of $63.5 \mathrm{kcal} /$ day, 444.5 kcal per week and 2667 for the mean treatment's duration ( 6 weeks) in the case of no energy intake reduction. Always considering the mean patients' weight, this daily amount of walking (at a speed of $4 \mathrm{~km} /$ hours) required to compensate for the decrease in AEE corresponds approximately to $26 \mathrm{~min}$ per day $(145.7 \mathrm{kcal} /$ hours for subjects with a mean weight of $47 \mathrm{~kg}$ ).

\section{DISCUSSION}

Most skeletal fractures involving the upper limb are treated non-operatively with cast immobilisation and may thus represent a frequent cause of reduction of the PA level in previously healthy children and teenagers. The most predictable consequences of cast immobilisation are loss of bone mineral tissue, substantial muscle atrophy and above all decrease of PA. ${ }^{25-27}$ By wearing an above elbow circular cast, children and teenagers lose the opportunity to cumulate energy expenditure through the thousands of intermittent muscular contractions occurring throughout the 16-hour wake period (Hamilton MT 2008 Curr cardiovasc Risk Report; Hamilton MT Diabetes 2007). This relative physical inactivity for prolonged periods of time will may also change body functions in different and unique ways. In fact, hundreds of genes and molecular processes are impaired during physical inactivity $^{28}$ due to biological mechanisms that are different from those activated by exercise. Clearly, sedentary activities, such as lying in bed or watching television, have 
some potent deleterious effects on biological attributes (particularly lipoproteins and high-density lipoprotein cholesterol) that are related to cardiovascular diseases. ${ }^{1}$ In addition to the resulting decreased energy expenditure, a calorie surplus is often associated with a sedentary lifestyle, ${ }^{2}$ phenomenon frequently encountered during periods with cast immobilisation.

PA is a multidimensional human behaviour, which is difficult to assess precisely under free-living conditions. However, it is currently admitted that accelerometer-based activity monitors provided valid measures of children's AEE. In an previous study, we have demonstrated that an AEE decrease was noted for children and teenagers during lower limb cast immobilisation, and that the reduction reached $2.4 \mathrm{kcal} / \mathrm{kg}$ during the waking hours. ${ }^{29}$ To the best of our knowledge, no studies have focused on sedentary behaviour due to upper limb cast immobilisation in children and teenagers, and the subsequent decreased PA-related metabolic effects. Thus, this is the first study that attempts to assess the decrease of PA's level by accelerometer and to quantify the decrease of AEE due to upper limb cast immobilisation. Our study shows study suggests that cast immobilisation leads to a $30 \%$ decrease of total PA, resulting to an AEE's reduction of $1.35 \mathrm{kcal} / \mathrm{kg}$ during the waking hours (mean: 750 min). Thus, for our fractured children and teenagers with a mean weight of $47 \mathrm{~kg}$, the observed energy gap (energy intake exceeding expenditure) represents an excess of $63.5 \mathrm{kcal} /$ day if no intake reduction was done, which corresponds approximately to $(145.7 \mathrm{kcal} /$ hours for subjects with a mean weight of $47 \mathrm{~kg}$ ). In comparison with the decrease of AEE encountered in patients with lower limb fractures, those with upper limb fractures will spend $43.8 \%$ energy with PA.

The prevalence of overweight status has tripled worldwide in the last 2 to 3 decades, including in developing countries and regions that are increasingly urbanised. The most important recognised causes appear to be a decline in PA and an increase in caloric intake, the two being closely linked. To place the finding of the present study into this perspective, it is good to remember that the US federal government has set measurable goals to reduce childhood obesity to $5 \%$ by 2010 and $10 \%$ lower than 2005-2008 levels by $2020 .^{30}$ To achieve these goals, the energy gap should be decreased by 160 and $184 \mathrm{kcal} /$ day, respectively. Thus, the energy gap excess noted in this study (63.5 kcal/day) may look insignificant at first glance, but our results suggest that decreased PA due to upper limb immobilisation corresponds to almost $35 \%-40 \%$ of the energy gap to reduce significantly childhood obesity.

When immobilised, most children will spend, as said above, more time watching television or playing computer games. These sedentary habits are known to promote increased energy intake $\mathrm{e}^{31-33}$ and may lead to additional weight gain. ${ }^{34}$ Therefore, the energy gap induced by physical inactivity is probably even more pronounced due to further increased energy intake. There are therefore some reasons to suspect that this excess amount of calories during a prolonged period of time could lead to the start of weight gain in any patients. To reduce this energy gap, subjects could either decrease energy intake or increase energy expenditure. According to our findings, the amount of time needed to compensate for the energy gap induced by inactivity in our population would represent almost 26 min of walking, walking at a speed of $4 \mathrm{~km} /$ hours per day of immobilisation. However, as expected during cast immobilisation, it is very difficult for children and teenagers to increase light PA, and even more challenging to achieve moderate to vigorous activity. For the 6 expected weeks of immobilisation periods, the energy gap excess will represent $2667 \mathrm{kcal}$, potentially leading to a gain of $355 \mathrm{~g}$ in fat mass, ${ }^{35}$ and the consumption of the energy gap excess will require after cast removing 1 hour per day of extrawalking at a speed of $4 \mathrm{~km} /$ hours for 18.3 days. To reduce this energy gap, subjects could either decrease energy intake or increase energy expenditure. Therefore, the physician has the primordial role to warn about potential weight gain and to encourage the child and family to change their nutritional habits. For example, one can (3.3 dL) of sugar-sweetened beverage (140 to $170 \mathrm{kcal} / \mathrm{can}$ ) can be replaced by water; snacks such as a chocolate bar (190 to $308 \mathrm{kcal}$ ), chocolate croissant $(280 \mathrm{kcal} / 100 \mathrm{~g})$ or potato chips $(160 \mathrm{kcal} / 30 \mathrm{~g})$ can be changed to more healthy food ( 1 apple $=58 \mathrm{kcal}$; 1 piece of whole bread $=48 \mathrm{kcal}$; one carrot $=29 \mathrm{kcal} ; 125$ $\mathrm{g}$ of plain yoghurt $=81 \mathrm{kcal})$; reduce television viewing by 1 hour $(167 \mathrm{kcal} / \text { day })^{36}$ and/or replace 26 min of sitting with slow walking $(124 \mathrm{kcal} /$ day for a subject of $47 \mathrm{~kg}){ }^{37}$

Finally, it is recognised that extremities' fractures may negatively impact on physical and psychosocial well-being. ${ }^{38}$ While most children recovered by 1 year postinjury, a considerable proportion still reported impaired physical and/or psychosocial health-related quality of life after limb's fractures. However, there are few data regarding PA during the recovery phase and the year following cast immobilisation. Do all fractured children and adolescents resume normal sporting activities or do they 'learn' bad habits during immobilisation? Thus, physicians should counsel their patients that although they may be limited in their sports function for some time after injury, it is anticipated that this will resolve by 1 year from the time of injury. During this period, a $47 \mathrm{~kg}$ child should walk every day for 1 hour during 18 days to lose the extra fat mass accumulated during the six of immobilisation. This can be reduced if moderate to vigorous instead of light PA is performed according to the time recommended by international guidelines. Therefore, a progressive increase of the time and the intensity of PA should be encouraged as soon as possible to reach at least 1 hour of moderate to vigorous intensity.

While accelerometers provide objective measurements, it is important to note some limitations of this study. They primarily measure locomotor activity when worn over the hip (typical placement position), and so miss upper body movement, and therefore underestimate 
the overall energy expenditure. Further, they cannot distinguish whether a person is carrying any weight (eg, walking carrying a heavy bag). ${ }^{39}$ Accelerometers do not inform on body posture; thus, they cannot distinguish between sitting and standing still. Second, there are activities during which accelerometers have to be removed (swimming) or do not accurately measure the intensity of exercise (cycling). These 'unmonitored' activities may result in underestimations of PA. Third, an evaluation of changes in energy intake before and during the immobilisation was not possible for obvious reason. Finally, we could not assess changes in body composition because of the impossibility to perform densitometry by dual-energy X-ray absorptiometry in adolescents with foreign materials and the impossibility to perform bioelectrical impedance analysis (BIA) or Plicometric measurements in our centre.

\section{CONCLUSION}

Immobilisation secondary to lower limb fracture leads to a decrease of AEE in injured children and teenagers compared with matched healthy controls. This energy gap represents each day a surplus of $63.5 \mathrm{kcal}$, which corresponds $26 \mathrm{~min}$ of walking at a speed of $4 \mathrm{~km} /$ hours. To limit fat mass accumulation, fractured children and adolescents should be warned about potential weight gain and coached to limit slightly energy intake. Emergency physicians and nurses are the first health providers that injured children meet and therefore have an important role for prevention information.

Acknowledgements The authors thank the patients and their parents for participation in the study.

Contributors DC: participated in the design, conception and coordination of the study, collected and treated the patients and revised the article for important intellectual content. XEM: participated in study's coordination, performed the CSA investigation, collected the data, realised data's interpretation and revised the article for important intellectual content. CD: performed the data analysis and the statistic alanalysis and revised the article for important intellectual content. ABRM: performed the CSA analysis and drafted the manuscript. AT-F: participated in drafting and revising critically the article for important intellectual content. All authors read and approved the final version of the manuscript to be submitted.

Funding This work was supported by grants from the Swiss National Science Foundation (SNSF \#405340-104611).

Competing interests None declared.

Patient consent Obtained.

Ethics approval The protocol was approved by the institutional ethics committee (protocol \# 04-057, ped 04-002), ethics committee of Geneva.

Provenance and peer review Not commissioned; externally peer reviewed.

Data sharing statement There is no available additional unpublished data from the study.

Open access This is an open access article distributed in accordance with the Creative Commons Attribution Non Commercial (CC BY-NC 4.0) license, which permits others to distribute, remix, adapt, build upon this work non-commercially, and license their derivative works on different terms, provided the original work is properly cited, appropriate credit is given, any changes made indicated, and the use is non-commercial. See: http://creativecommons.org/licenses/by-nc/4.0/

\section{REFERENCES}

1. Hamilton MT, Healy GN, Dunstan DW, et al. Too little exercise and too much sitting: inactivity physiology and the need for new recommendations on sedentary behavior. Curr Cardiovasc Risk Rep 2008;2:292-8.

2. Epstein $\mathrm{LH}$, Roemmich JN, Robinson JL, et al. A randomized trial of the effects of reducing television viewing and computer use on body mass index in young children. Arch Pediatr Adolesc Med 2008;162:239-45.

3. Hamilton MT, Hamilton DG, Zderic TW. Role of low energy expenditure and sitting in obesity, metabolic syndrome, type 2 diabetes, and cardiovascular disease. Diabetes 2007;56:2655-67.

4. Landin L, Nilsson BE. Bone mineral content in children with fractures. Clin Orhopaedlcs Relat Res 1983:292-6.

5. Lyons RA, Delahunty AM, Kraus D, et al. Children's fractures: a population based study. Inj Prev 1999;5:129-32.

6. Thomas EM, Tuson KW, Browne PS. Fractures of the radius and ulna in children. Injury 1975;7:120-4.

7. Cheng JC, Shen WY. Limb fracture pattern in different pediatric age groups: a study of 3,350 children. J Orthop Trauma 1993;7:15-22.

8. Johnson PG, Szabo RM. Angle measurements of the distal radius: a cadaver study. Skeletal Radiol 1993;22:243-6.

9. Reed MH. Fractures and dislocations of the extremities in children. J Trauma 1977;17:351-4.

10. Worlock P, Stower M. Fracture patterns in Nottingham children. $J$ Pediatr Orthop 1986;6:656-60.

11. Charansonney OL, Després JP. Disease prevention-should we target obesity or sedentary lifestyle? Nat Rev Cardiol 2010;7:468-72.

12. van Herpen NA, Schrauwen-Hinderling VB. Lipid accumulation in non-adipose tissue and lipotoxicity. Physiol Behav 2008;94:231-41.

13. Ceroni D, Martin X, Delhumeau C, et al. Decrease of physical activity level in adolescents with limb fractures: an accelerometry-based activity monitor study. BMC Musculoskelet Disord 2011;12:87.

14. Brage S, Wedderkopp N, Ekelund U, et al. Features of the metabolic syndrome are associated with objectively measured physical activity and fitness in Danish children: the European Youth Heart Study (EYHS). Diabetes Care 2004;27:2141-8.

15. Craig CL, Marshall AL, Sjöström M, et al. International physical activity questionnaire: 12 -country reliability and validity. Med Sci Sports Exerc 2003;35:1381-95.

16. Ekelund U, Sardinha LB, Anderssen SA, et al. Associations between objectively assessed physical activity and indicators of body fatness in 9- to 10-y-old European children: a population-based study from 4 distinct regions in Europe (the European Youth Heart Study). Am J Clin Nutr 2004;80:584-90.

17. Schmidt MD, Freedson PS, Chasan-Taber L. Estimating physical activity using the CSA accelerometer and a physical activity log. Med Sci Sports Exerc 2003;35:1605-11.

18. Treuth MS, Sherwood NE, Butte NF, et al. Validity and reliability of activity measures in African-American girls for GEMS. Med Sci Sports Exerc 2003;35:532-9.

19. Brage S, Wedderkopp N, Ekelund U, et al. Objectively measured physical activity correlates with indices of insulin resistance in Danish children. The European Youth Heart Study (EYHS). Int J Obes Relat Metab Disord 2004;28:1503-8.

20. Ekelund U, Åman J, Westerterp K. Is the ArteACC index a valid indicator of free-living physical activity in adolescents? Obes Res 2003;11:793-801.

21. Riddoch CJ, Bo Andersen L, Wedderkopp N, et al. Physical activity levels and patterns of 9- and 15-yr-old European children. Med Sci Sports Exerc 2004;36:86-92.

22. Hayden-Wade HA, Coleman KJ, Sallis JF, et al. Validation of the telephone and in-person interview versions of the 7-day PAR. Med Sci Sports Exerc 2003;35:801-9.

23. Puyau MR, Adolph AL, Vohra FA, et al. Validation and calibration of physical activity monitors in children. Obes Res 2002;10:150-7.

24. Ceroni D, Martin X, Lamah L, et al. Recovery of physical activity levels in adolescents after lower limb fractures: a longitudinal, accelerometry-based activity monitor study. BMC Musculoskelet Disord 2012;13:131.

25. Behm DG, St-Pierre DM. Fatigue characteristics following ankle fractures. Med Sci Sports Exerc 1997;29:1115-23.

26. Bloomfield SA. Changes in musculoskeletal structure and function with prolonged bed rest. Medicine \&amp Science in Sports \&amp Exercise 1997;29:197-206.

27. Edgerton VR, Roy RR, Allen DL, et al. Adaptations in skeletal muscle disuse or decreased-use atrophy. Am J Phys Med Rehabil 2002;81(11 Suppl):S127-S147.

28. Bey L, Hamilton MT. Suppression of skeletal muscle lipoprotein lipase activity during physical inactivity: a molecular reason to maintain daily low-intensity activity. J Physiol 2003;551(Pt 2):673-82. 
29. Maggio AB, Martin XE, Ceroni D. Activity-related energy expenditure during lower limb cast immobilization in children. $J$ Pediatr Orthop $B$ 2017;26:217-21.

30. Wang YC, Orleans CT, Gortmaker SL. Reaching the healthy people goals for reducing childhood obesity: closing the energy gap. Am J Prev Med 2012;42:437-44.

31. Mekhmoukh A, Chapelot D, Bellisle F. Influence of environmental factors on meal intake in overweight and normal-weight male adolescents. A laboratory study. Appetite 2012;59:90-5.

32. Rey-López JP, Vicente-Rodríguez G, Répásy J, et al. Food and drink intake during television viewing in adolescents: the Healthy Lifestyle in Europe by Nutrition in Adolescence (HELENA) study. Public Health Nutr 2011;14:1563-9.

33. Ford $\mathrm{C}$, Ward $\mathrm{D}$, White $\mathrm{M}$. Television viewing associated with adverse dietary outcomes in children ages 2-6. Obes Rev 2012;13:1139-47.
34. Rey-López JP, Vicente-Rodríguez G, Biosca M, et al. Sedentary behaviour and obesity development in children and adolescents. Nutr Metab Cardiovasc Dis 2008;18:242-51.

35. Hill JO, Wyatt HR, Reed GW, et al. Obesity and the environment: where do we go from here? Science 2003;299:853-5.

36. Wiecha JL, Peterson KE, Ludwig DS, et al. When children eat what they watch: impact of television viewing on dietary intake in youth. Arch Pediatr Adolesc Med 2006;160:436-42.

37. Wang YC, Gortmaker SL, Sobol AM, et al. Estimating the energy gap among US children: a counterfactual approach. Pediatrics 2006;118:e1721-e1733.

38. Ding R, McCarthy ML, Houseknecht E, et al. The health-related quality of life of children with an extremity fracture: a one-year follow-up study. J Pediatr Orthop 2006;26:157-63.

39. Lee IM, Shiroma EJ. Using accelerometers to measure physical activity in large-scale epidemiological studies: issues and challenges. Br J Sports Med 2014;48:197-201. 